\title{
The Isolation Rate of Pseudomonas aeruginosa Opportunistic Pathogen and their Antimicrobial Responses in HIV-1 Positive and Negative Diarrhoea Patients at North-West Part of Ethiopia Berhanu Andualem*
}

Department of Biotechnology, Natural and Computational Sciences Faculty, University of Gondar, Ethiopia

\begin{abstract}
Background: Pseudomonas aeruginosa is an opportunistic pathogen in immune-compromised patients. However, reports of infections of Pseudomonas aeruginosa were limited in patients infected with HIV. The aim of the study was to determine the frequency of isolation and sensitivity pattern of $P$. aeruginosa against the commonly used antibiotics in HIV-1 positive and negative diarrheic patients.
\end{abstract}

Methods: Laboratory based cross-sectional study of 312 (199 HIV seropositive and 113 HIV seronegative) diarrheic patients of both genders were investigated at University of Gondar Hospital, Gondar, Ethiopia. P. aeruginosa isolates were isolated from diarrheic stool and identified as per standard methods and tested for antimicrobial susceptibility.

Result: Pseudomonas aeruginosa was isolated from $29.5 \%$ (92/312) of diarrheic patients, of which $20.5 \%$ were from HIV positive subjects. Out of $58 \mathrm{H}$. zoster positive diarrhoea patients, $47(81 \%)$ were HIV positive and $11(19 \%)$ were HIV seronegative $(P<0.002)$. The proportion of patients with weight loss and $P$. aeruginosa infection was significantly higher in those with HIV co-infection $(P<0.05)$. Among $P$. aeruginosa isolates $96.4 \%, 78.6 \%, 73.2 \%$, $71.4 \%, 68.8 \%$ and $62.5 \%$ were sensitive to polymyxin B, gentamycin, norfloxacin, kanamycin, ciprofloxacin and nalidixic acid, respectively. The highest resistance observed was against ampicillin (96.4\%), tetracycline $(92 \%)$, trimethoprim-sulphamethoxazole $(89.3 \%)$ and chloramphenicol $(74.1 \%)$. One hundred nine $(97.3 \%)$ out of the $112 P$. aeruginosa isolates were found to be multiple drug resistant.

Conclusion: Though high proportion of $P$. aeruginosa strains were reported in HIV seropositive diarrheic patients, detailed investigation is important to get comprehensive information for better treatment of diarrhoea in HIV IAIDS patients. In this study, ampicillin, tetracycline, trimethoprim-sulphamethoxazole and chloramphenicol may not be used for the treatment of $P$. aeruginosa infection, unless culture and sensitivity tests are done prior to treatment. Effective public health measures such as prevention of infections through quality environmental sanitation and personal hygiene should be emphasized.

Keywords: P. aeruginosa; HIV-1; Diarrhea; Prevalence; Antimicrobial sensitivity

\section{Introduction}

HIV/AIDS pandemic is still extremely dynamic and growing worldwide. In the world, about 33.2 million people are estimated to be infected with HIV/AIDS [1]. From this more than 22.5 million are expected to live in Sub-Saharan Africa [1]. HIV is now the leading cause of death worldwide among the age group of 15-24. Among the most heavily HIV/AIDS affected countries, Ethiopia is the third next to India and South Africa in 2005 [2]. The prevalence of HIV infection in Ethiopia is currently over 3.5\% [3]. HIV, in Ethiopia, is mostly associated with opportunistic infections such as candidiasis, tuberculosis, CNS mass lesion [4] and diarrhea [5].

Diarrheal diseases are one of the major causes of morbidity and mortality in developing countries [6]. The situation is severe in subSaharan Africa, a region where prevalence of HIV is high [7]. Diarrhea, the passage of loose or watery stools at least three times in 24 hours, is one of the clinical manifestations of HIV infection and usually tends to be chronic [6]. Chronic diarrhea, an episode that begins acutely and lasts for more than four weeks [6], in tropical countries is associated with weight loss and is often the presenting illness of HIV infected individuals. This diarrhea wasting syndrome in association with a positive HIV serology test is an AIDS defining illness in the World Health Organization's classification [8]. Diarrhoea occurs in up to $70 \%$ of the patients infected with HIV in Africa [9]. In Ethiopia, as in other
sub-Saharan Africa, morbidities from diarrhoeal diseases [6] and HIV/ AIDS $[10,11]$ are serious health problems. Of those bacterial infections, $P$. aeruginosa is one of the opportunistic bacterium in HIV/AIDS patients with diarrhea [12].

Pseudomonas aeruginosa is a Gram-negative, aerobic rod belonging to the bacterial family Pseudomonadaceae. $P$. aeruginosa is an opportunistic pathogen, meaning that it exploits when there is some break in the host defense to initiate an infection [13]. It causes different infections such as, urinary tract, respiratory system, soft tissue, bone and joint, gastrointestinal and a variety of systemic infections, dermatitis and bacteremia particularly in patients with severe burns, cancer and AIDS patients [14]. One characteristic of $P$. aeruginosa infections in

*Corresponding author: Berhanu Andualem, Department of Biotechnology, Natural and Computational Sciences Faculty, University of Gondar, P.O. Box 196, Gondar, Ethiopia, Tel: + 251918-70-00-27; Fax: 25158- 14- 19-31; E-mail: anberhanu2007@yahoo.com

Received January 28, 2012; Accepted April 2, 2012; Published April 4, 2012

Citation: Andualem B (2012) The Isolation Rate of Pseudomonas aeruginosa Opportunistic Pathogen and their Antimicrobial Responses in HIV-1 Positive and Negative Diarrhoea Patients at North-West Part of Ethiopia. J AIDS Clinic Res 3:148. doi:10.4172/2155-6113.1000148

Copyright: (c) 2012 Andualem B. This is an open-access article distributed unde the terms of the Creative Commons Attribution License, which permits unrestricted use, distribution, and reproduction in any medium, provided the original author and source are credited. 
Citation: Andualem B (2012) The Isolation Rate of Pseudomonas aeruginosa Opportunistic Pathogen and their Antimicrobial Responses in HIV-1 Positive and Negative Diarrhoea Patients at North-West Part of Ethiopia. J AIDS Clinic Res 3:148. doi:10.4172/2155-6113.1000148

Page 2 of 7

HIV-infected population is the predominance of community-acquired rather than nosocomial cases [15-17].

Diagnosis of $P$. aeruginosa infection depends up on isolation and laboratory identification of the bacterium. It grows well on most laboratory media. It is identified on the basis of its Gram morphology, inability to ferment lactose, positive oxidase reaction, its fruity odor and ability to grow at $42^{\circ} \mathrm{C}$ [18]. Fluorescence under ultraviolet light is helpful for early identification of $P$. aeruginosa colonies $[19,20]$.

Pseudomonas aeruginosa is notorious for its resistance to antibiotics and is therefore, a particularly dangerous and dreaded pathogen $[21,22]$. The bacterium is naturally resistant to many antibiotics due to the permeability barrier afforded by its outer membrane lipopolysaccharides (LPS). Also, its tendency to colonize surfaces in a biofilm form makes the cells impervious to therapeutic concentrations antibiotics [22]. Since its natural habitat is the soil, living in association with the bacilli, actinomycetes and molds, it has developed resistance to a variety of their naturally occurring antibiotics [23]. Moreover, $P$. aeruginosa maintains antibiotics resistance plasmids, both R-factors and RTFs, and it is able to transfer these genes by means of transduction and conjugation [24]. Generally, P. aeruginosa develops resistance to nearly any antimicrobial agent. Resistance is problematic at three levels: intrinsic resistance, acquired resistance and emergence resistance during therapy [25]. P. aeruginosa is frequently resistant to many commonly used antibiotics. Each of them must be considered when choosing an antibiotic regiment for patients infected with $P$. aeruginosa [26-28].

In Ethiopia, as far as my exploration is concerned, there are no studies conducted on the prevalence and sensitivity pattern of $P$. aeruginosa against the commonly used antibiotics in diarrheic patients with and without HIV infection. Therefore, the objective of this study is to determine the frequency of isolation and sensitivity pattern of $P$. aeruginosa against the commonly used antibiotics in HIV-1 positive and negative diarrheic patients. The outcome of this study may help as baseline information for empirical treatment of HIV 1 positive diarrheic patients affected by P. aeruginosa.

\section{Materials and Methods}

\section{Study design and subjects}

In this cross-sectional study, consecutive diarrheic patients diagnosed at the outpatient department of the University of Gondar Hospital, in Gondar, Ethiopia were included. Informed consent was obtained from all subjects and the study was approved by the Research Ethics Committee of the University.

Chronic diarrhea was defined as an average of three or looser watery bowl movement per day for at least two weeks before the study [29]. Acute diarrhea was defined as an episode that lasted less than 14 days [29]. All subjects underwent physical examination. Socio-demographic and clinical data were recorded by medical doctors on structured and pre-tested questionnaires.

\section{The sample size}

The sample size for the study was calculated by considering a $95 \%$ level of confidence, $90 \%$ proportion of the study done in Addis Ababa [30] and Jimma [31] respectively, 5\% margin and 20\% contingency. As the result, 312 patients with diarrhea were included in the study, out of which 199 were HIV seropositive and 113 HIV seronegative.

\section{HIV serology}

After obtaining informed consent and appropriate pre-test counseling, about $5 \mathrm{ml}$ of venous blood was taken from each subject and sera were separated by centrifugation and stored at $-20^{\circ} \mathrm{C}$ until used. The presence of HIV antibodies was determined by an enzyme linked immunosorbent assay following the manufacturer's instruction (Vironostica HIV Uni-Form II plus O, Organon Teknika, Boxtel, the Netherlands) [32].

\section{Stool collection and isolation of pathogens}

Diarrheic stool specimens were collected as fresh in sterile containers and processed immediately after collection following standard procedures [33]. The specimens were cultured on the MacConkey agar (BBL). All the inoculated plates of McConkey agar were incubated at $42^{\circ} \mathrm{C}$ for $48 \mathrm{hrs}$.

The $P$. aeruginosa isolates were identified based on colony characteristics, gram staining methods and by various biochemical tests as given below. In brief, they were identified on the basis of their Gram morphology, inability to ferment lactose, oxidase and hydrogen peroxide reaction, its fruity odor and its ability to grow at $42^{\circ} \mathrm{C}$ [34]. A single colony of non-lactose fermenting type from MacConkey plates was aseptically picked and inoculated in about $3 \mathrm{ml}$ of nutrient broth and incubated at $35-37^{\circ} \mathrm{C}$ for $2-4$ hours until growth was ascertained by turbidity. From this broth culture, identification of $P$. aeruginosa was performed with the help of biochemical tests which routinely included triple sugar iron (TSI) agar slant, lysine iron (LI) agar slant, Urea agar slant, Simmon's citrate agar slant, Shahidi Indole Motility (SIM) medium, Mannitol broth (1\%) and glucose broth (1\%). Biochemical results were interpreted by using Bergey's manual [35].

\section{Antimicrobial sensitivity testing}

Susceptibility testing of all strains was done on Muller-Hinton agar with commercial antibiotic discs using Kirby-Bauer method [36]. Each isolate was sub-cultured on a plate of MacConkey agar and incubated at $37^{\circ} \mathrm{C}$ for 18 to 24 hours. From a pure culture of each isolate 4 to 5 similar colonies were randomly selected and transferred to a test tube of Trypticase Soy broth by touching the top of each colony with a sterilized wire loop [34]. Trypticase Soy broth incubated at $37^{\circ} \mathrm{C}$ for 8 hours to obtain moderate turbidity. The suspension (a portion of it) was diluted with a sterile saline to obtain turbidity visually equal to that of the standard of McFarland 2 [37].

Susceptibility testing of all strains against ampicillin (Amp) 10 $\mu \mathrm{g}$; chloramphenicol (Chl) $30 \mu \mathrm{g}$; gentamycin (Gen) $10 \mu \mathrm{g}$; nalidixic acid (Nal) $30 \mu$; polymyxin B (Pol) $30 \mu \mathrm{g}$; norfloxacin (Nor) $30 \mu \mathrm{g}$; tetracycline (Tet) $30 \mu$; kanamycin (Kan) $30 \mu$; ciprofloxacin (Cip) 5 $\mu \mathrm{g}$ and trimethoprim-sulphamethoxazole (Sxt) $25 \mu \mathrm{g}$ were carried out using standard method (Andualem and Geyid, 2003). Staphylococcus aureus (ATCC 27813) and Escherichia coli (ATCC5922) strains susceptible to all the antibiotics tested were used as control.

Finally, diameters of inhibition zones were measured in millimeters using a sliding caliper, which is held on the back of the inverted plate. The sizes of the zones of inhibition were interpreted by using zone diameter interpretive standards [38]. The intermediate readings were considered as sensitive for a purpose of assessment of the data. Multiple drug resistance was defined as a given bacterium which is resistant to more than one antibiotic. 


\section{Statistical analyses}

Data were analyzed using SPSS version 16 statistical package.

\begin{tabular}{|l|c|c|c|}
\hline & \multicolumn{2}{|c|}{ HIV serostatus } & \\
\hline Characteristics & HIV positive No. $\%)$ & HIV negative No. (\%) & Total No. (\%) \\
\hline Total & $199(63.8)$ & $113(36.2)$ & $312(100)$ \\
\hline Sex & & & \\
\hline Male & $106(34.0)$ & $74(23.7)$ & $180(57.7)$ \\
\hline Female & $93(29.8)$ & $39(12.5)$ & $132(42.3)$ \\
\hline Age & & & \\
\hline $15-24$ & $25(8.0)$ & $50(16.0)$ & $75(24.0)$ \\
\hline $25-34$ & $102(32.7)$ & $33(10.6)$ & $135(43.3)$ \\
\hline $35-44$ & $55(17.6)$ & $16(5.1)$ & $71(22.7)$ \\
\hline$>45$ & $17(5.4)$ & $14(4.5)$ & $31(9.9)$ \\
\hline Marital status & & & \\
\hline Married & $99(31.7)$ & $57(18.3)$ & $156(50.0)$ \\
\hline Single & $56(17.9)$ & $49(15.7)$ & $105(33.6)$ \\
\hline Divorced & $39(12.5)$ & $4(1.3)$ & $43(13.8)$ \\
\hline Widow & $5(1.6)$ & $3(1.0)$ & $8(2.6)$ \\
\hline Occupation & & & \\
\hline Gov. employee & $43(13.8)$ & $23(7.4)$ & $66(21.2)$ \\
\hline Farmer & $31(9.7)$ & $22(7.1)$ & $53(17.0)$ \\
\hline Student & $12(3.8)$ & $36(11.5)$ & $48(15.3)$ \\
\hline House wife & $30(9.6)$ & $12(3.8)$ & $42(13.4)$ \\
\hline Others & $60(19.2)$ & $43(13.8)$ & $103(33)$ \\
\hline Type of diarrhea & & & \\
\hline Acute & $79(25.3)$ & $66(21.2)$ & $145(46.5)$ \\
\hline Chronic & $120(38.5)$ & $47(15)$ & $167(53.5)$ \\
\hline Herpes zoster & $161(51.6)$ & $38(12.2)$ & $199(63.8)^{*}$ \\
\hline Parasite & $61(19.6)$ & $38(12.2)$ & $95(31.8)^{*}$ \\
\hline Chisqure & & & \\
$*$
\end{tabular}

Chi-square test at significance level $\mathrm{P}<0.05$; ${ }^{\mathrm{P}}<0.05$ compared to HIV seronegatives

Table 1: Characteristics of diarrheic patients by HIV serostatus, University of Gondar Hospital, 2003/4.
Comparisons P. aeruginosa positive among HIV patients with diarrhoea were made using both Chi-square test at significance level $\mathrm{P}<0.05$ and compared means (student $\mathrm{t}$ test; independent samples test). $\mathrm{P}$ values less than 0.05 were considered statistically significant.

\section{Results}

Table 1 shows socio-demographic and clinical features of the patients by HIV serostatus. A total of 312 diarrheic patients were included in the study. Of this, one hundred eighty (57.7\%) were males and $132(42.3 \%)$ were females. Their mean age was 29 (range 15 to 67 years). A significant number of the patients were in the age group of 25 to 44 years. On the age group 15-24 HIV seropositive diarrheoa patients, the proportion of males and females was $3.5 \%$ to $4.5 \%$, respectively. It was also observed that the proportion of males and females within the age groups greater than 34 years were $14.7 \%$ and $8.3 \%$, respectively $(\mathrm{P}<0.043)$. The prevalence of HIV in diarrhea patients with regard to marital status ( $\mathrm{P}$ $<0.01)$ and occupation distribution $(\mathrm{P}<0.01)$ has shown significant variation in the study subjects. Of the diarrheoa patients, $66(21.2 \%)$ government employees, 53 (17.0\%) farmers, 48 (15.3\%) students, 42 (13.4\%) house wives, and 103 (33\%) others were found to be HIV positive. Acute and chronic diarrhea was diagnosed in $46.5 \%$ and $53.5 \%$ of the patients, respectively. Among patients having acute diarrhoea, 79 (25.5\%) and $66(21.2 \%)$ were HIV positive and negative, respectively. In the case of patients having chronic diarrhoea, 59 (18.9\%) and 108 (34.6\%) were HIV positive and negative, respectively. The prevalence of HIV infection in the patients was $63.8 \%$ (199/312).

In this investigation, the association of the history of Herpes zoster in HIV seropositive and negative diarrheic patients was seen. Out of 199 H. zoster positive diarrhoea patients, 161 (80.9\%) were HIV positive and $38(19.1 \%)$ were HIV seronegative $(\mathrm{P}<0.002)$ (Table 1$)$. Intestinal parasites were detected in $61(19.6 \%)$ and $38(12.2 \%)$ of HIV negative and HIV positive patients out of the total (312) diarrheic patients, respectively $(\mathrm{P}<0.002)$.

\begin{tabular}{|c|c|c|c|c|c|c|c|}
\hline \multirow[t]{3}{*}{ Characteristics } & & \multicolumn{4}{|c|}{ HIV serostatus } & \multirow[t]{3}{*}{ Total No. (\%) } & \multirow[t]{3}{*}{ P-value } \\
\hline & & \multicolumn{2}{|c|}{ HIV positive (\%) } & \multicolumn{2}{|c|}{ HIV negative (\%) } & & \\
\hline & & P. aeruginosa Positive & P. aeruginosa Negative & P. aeruginosa Positive & $P$. aeruginosa Negative & & \\
\hline$P$. aeruginosa isolates & & $64(32.2)$ & $135(67.8)$ & $28(24.8)$ & $85(75.2)$ & $312(100)$ & 0.004 \\
\hline \multirow[t]{4}{*}{ Nature of diarrhea } & Watery & $31(15.8)$ & $58(29.1)$ & $10(8.8)$ & $35(31)$ & $134(42.9)$ & 0.514 \\
\hline & Bloody & $21(10.6)$ & $35(17.6)$ & $8(7.1)$ & $31(27.4)$ & $95(30.4)$ & \\
\hline & Mucoid & $12(6)$ & $42(21.1)$ & $10(8.8)$ & $19(16.8)$ & $83(26.6)$ & \\
\hline & Total & $64(32.2)$ & $135(67.8)$ & $28(24.8)$ & $85(75.2)$ & $312(100)$ & \\
\hline \multirow[t]{3}{*}{ Weight loss } & Yes & $61(30.7)$ & $119(59.8)$ & $12(10.6)$ & $27(23.9)$ & $219(70.20$ & 0.0001 \\
\hline & No & $3(1.5)$ & $16(8)$ & $16(14.2)$ & $58(51.3)$ & $93(29.8)$ & \\
\hline & Total & $64(32.2)$ & $135(67.8)$ & $28(24.8)$ & $85(75.2)$ & $12(100)$ & \\
\hline \multirow[t]{3}{*}{ Abdominal cramp } & Yes & $25(12.6)$ & $35(17.6)$ & $12(10.6)$ & $26(23)$ & $98(31.4)$ & 0.218 \\
\hline & No & $39(4.5)$ & $100(50.3)$ & $16(14.2)$ & $59(52.2)$ & $214(68.6)$ & \\
\hline & Total & $64(32.2)$ & $135(67.8)$ & $28(24.8)$ & $85(75.2)$ & $312(100)$ & \\
\hline \multirow[t]{3}{*}{ Tennesmus } & Yes & $15(7.5)$ & $18(9)$ & $8(7.1)$ & $16(14.2)$ & $57(18.3)$ & 0.045 \\
\hline & No & $49(24.6)$ & $117(58.8)$ & $20(17.7)$ & $69(61.1)$ & $255(81.7)$ & \\
\hline & Total & $64(32.2)$ & $135(67.8)$ & $28(24.8)$ & $85(75.2)$ & $312(100)$ & \\
\hline \multirow[t]{3}{*}{ Previous episode } & Yes & $10(5)$ & $11(5.5)$ & $5(4.4)$ & $13(11.5)$ & $39(12.5)$ & 0.007 \\
\hline & No & $54(27.1)$ & $124(62.3)$ & $23(20.4)$ & $72(63.7)$ & $273(87.5)$ & \\
\hline & Total & $64(32.2)$ & $135(67.8)$ & $28(24.8)$ & $85(75.2)$ & $312(100)$ & \\
\hline Herpes zoster & & $47(29.2)$ & $114(70.8)$ & $26(68.4)$ & $12(31.6)$ & $199(100)$ & 0.001 \\
\hline
\end{tabular}

Compared means (student $t$ test; independent samples test) was used at $P$ values less than 0.05

Table 2: Clinical symptoms and diarrhea status in association with that of $P$. aeruginosa isolates in HIV seropositive and negative diarrhoea patients, University of Gondar Hospital, 2003/4. 


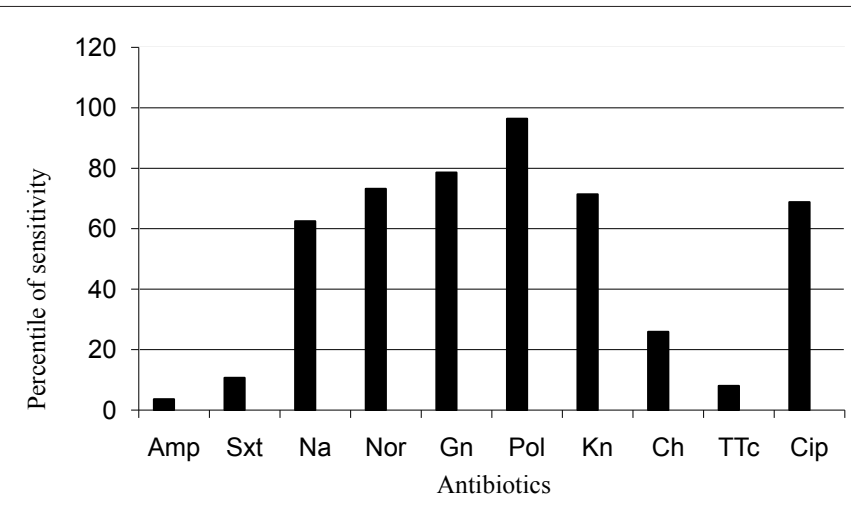

Amp = Ampicillin; Sxt $=$ Trimethoprim-sulphamethoxazole; $\mathrm{Na}=$ Nalidixic acid; Nor = Norfloxacin; $\mathrm{Gn}=$ Gentamycin; Pol = Poymyxin B; Kn = Kanamycin; $\mathrm{Ch}=$ Chloramphenicol; TTc = Tetracycline; Cip = Ciprofloxacin

Figure 1: Sensitivity pattern of $P$. aeruginusa isolates against certain antibiotics

The prevalence of $P$. aeruginosa isolates in HIV positive and negative subjects was investigated (Table 2). The most important finding of this study was that out of the total diarrhoea patients, 92 (29.5\%) was $P$. aeruginosa positive in both HIV positive and negative study subjects. Out of the total $P$. aeruginosa isolates, $64(20.5 \%)$ were isolated from HIV positive and $28(9 \%)$ from HIV negative diarrhoea patients $(\mathrm{P}<$ 0.05). Of the total 199 (100\%) H. zoster infected diarrheic patients, 161 $(80.9 \%)$ and 38 (19.1\%) were HIV positive and negative, respectively. From both HIV and $P$. aeruginosa positive study subjects (64), 47 (73.4\%) were positive for $H$. zoster while the rest 17 (26.6\%) negative for H. zoster $(\mathrm{P}<0.05)$ (Table 2).

Clinical symptoms and diarrhea status in association with that of $P$. aeruginosa isolates in HIV seropositive and negative diarrhoea patients is presented in Table 2. In this study, nature of diarrhea and abdominal cramp of such diarrhoea were not statistically associated with $P$. aeruginosa isolates $(\mathrm{P}>0.05)$. On the other hand, marked weight loss was observed in $32.2 \%$ and 24.8 of patients with HIV seropositive and HIV seronegative, respectively. The proportion of patients with weight loss and P. aeruginosa infection was significantly higher in those with HIV co-infection $(\mathrm{P}<0.05)$. Based on the independent samples test analysis of HIV serostatus result, weight loss, and parasites as independent variables and $P$. aeruginosa as dependent variable, has been shown significant association $(\mathrm{P}<0.05)$ between the parameters and prevalence of $P$. aeruginosa.

Antimicrobial sensitivity test of $P$. aeruginosa isolates against the chosen 10 antimicrobial agents are present on Figure 1. All the strains were not $100 \%$ sensitive to any of the chosen antibiotic agents but $96.4 \%$, $78.6 \%, 73.2 \%, 71.4 \%, 68.8 \%$ and $62.5 \%$ of $P$. aeruginosa strains were sensitive to Pol, Gen, Nor, Kan, Cip and Nal, respectively. The highest resistance pattern was observed against chloramphenicol (74.1\%), Sxt (89.3\%), Tet (92\%) and Amp (96.4\%).

Resistance against one or more antibiotics is shown in Table 3. Out of the 112 P. aeruginosa strains, 109 (97.3\%) showed multiple resistance. In all, 36 different patterns of resistance were noted. The frequency of Amp, Sxt, Nal, Nor, Gn, Kn, Ch, Ttc, Cip, and Amp, Sxt, Ch, Tet pattern of resistance are $19(17 \%)$ and 28 (25\%), respectively, which are the highest in comparison with other pattern of resistance. Three and five pattern of resistance were observed in 16 (14.3\%) and 17 (15.3\%) P. aeruginosa isolates, respectively. Pseudomonas aeruginosa isolates with greater than three pattern of antimicrobial resistance account for 89 (79.6\%). In this finding, there is no any strain, which is sensitive, or resistance against to all antimicrobial agents.

\section{Discussion}

HIV infection has become the dominant health problem in many parts of sub-Saharan Africa, including Ethiopia [39]. The result of this study in terms of HIV infection agrees with that indicated on the 2005 UNAIDS report [3]. It was observed that the highest infection rates are concentrated in the 15-34 year age group. Within this age group, prevalence among females was found to be greater than that of males. Other than gender, marital status and occupation have also shown impact on the distribution of HIV. The association of $H$. zoster infection and HIV was also found to be significantly $(\mathrm{p}<0.05)$ high $161 / 199$ (80.9\%). H. zoster infection was one of the most common HIV-related opportunistic infections and diseases in HIV seropositive patients $[40,41]$. According to this study, the infection rate of $H$. zoster in both HIV and P. aeruginosa positive was $73.4 \%$. This is may be due to weak immune response of HIV positive study subjects. As well known, both $H$. zoster $[40,41]$ and $P$. aeruginosa [15] infections were the most common opportunistic infections in HIV positive individuals.

One of the major manifestations of the HIV disease in the region is the diarrhea $[42,43]$. In this investigation, chronic diarrhoea was found to be more common than acute diarrhoea in HIV positive subjects. On the other hand, acute diarrhoea was more common than chronic diarrhoea in HIV negative subjects.

Intestinal parasitism occurs widely throughout Ethiopia [44]. It was reported that intestinal parasites were one of the causative agents of diarrhoea in HIV seropositive patients [5,45]. In line with these reports; we found a high prevalence (19.6\%) of intestinal parasites in HIV seropositive diarrheic patients included in the present study. Earlier data suggest that intestinal parasite infections can affect the nutritional status of infected people through modification of food intake, digestion and absorption capacity [46]. Acquired immunodeficiency syndrome (AIDS) caused by HIV infection predisposes individuals to several diarrhoeagenic bacterial diseases of various species [47] in addition to several viral, protozoal and parasitic etiological agents [48]. This study was designed to investigate the prevalence and antimicrobial responses of $P$. aeruginosa isolated from HIV seropositive and negative diarrheic patents.

Pseudomonas aeruginosa is important opportunistic pathogens of bacteria in HIV-infected host [15]. This study showed a high prevalence of $P$. aeruginosa in diarrheic patients with or without HIV co-infection in Northwest Ethiopia (29.5\%). In this investigation, the prevalence of

\begin{tabular}{|c|c|}
\hline Resistance Pattern & No of isolates (\%) \\
\hline One & $3(2.7)$ \\
\hline Two & $4(3.8)$ \\
\hline Three & $16(14.3)$ \\
\hline Four & $34(30.4)$ \\
\hline Five & $17(15.3)$ \\
\hline Six & $10(9.0)$ \\
\hline Seven & $5(4.5)$ \\
\hline Eight & $4(3.4)$ \\
\hline Nine & $19(17)$ \\
\hline Sensitive to all & $0(0)$ \\
\hline Resistance to all & $0(0)$ \\
\hline Total & $112(100)$ \\
\hline
\end{tabular}

Table 3: Drug resistance pattern of $P$. aeruginosa isolates. 
Citation: Andualem B (2012) The Isolation Rate of Pseudomonas aeruginosa Opportunistic Pathogen and their Antimicrobial Responses in HIV-1 Positive and Negative Diarrhoea Patients at North-West Part of Ethiopia. J AIDS Clinic Res 3:148. doi:10.4172/2155-6113.1000148

the isolation of $P$. aeruginosa in HIV seropositive subjects was $64 / 199$ (20.5\%), which was lower than $41 / 135(30.7 \%)$ isolates from HIVinfected patients [49]. However, the result of this study was almost the same with the report of (19.2\%) Osazuwa et al. [50], in Benin but higher than the isolated $(8.7 \%)$ and $(4.7 \%)$ strains reported by Olayinka et al. [51] and Hernandez et al. [52], respectively. Even the isolation rate is high in some studies [51,52], $P$. aeruginosa infection is not frequent bacterial disease in highly immunodeficient HIV-infected patients. It may be fatal in the advanced stages of HIV diseases, especially when patients have taken the common and cheap available antibiotics [53] and the society with poor hygiene conditions. The incidence of $P$. aeruginosa infections in HIV/AIDS patients appears to be on the rise [54].

The results of this study revealed that the prevalent rate of $P$. aeruginosa is high in HIV seropositive diarrheic patients. In this finding, HIV positive patients without $P$. aeruginosa were also affected by diarrhoea. This shows that diarrhoea may be associated with other diarrhoeagenic agents or mechanisms rather than P. aeruginosa [55]. Then, detail investigation has to be made in order to get comprehensive information for better treatment of diarrhoea in HIV/AIDS patients.

In this study, all the isolates were resistant to the cheap, commonly available antibiotics, such as Tet, Sxt and Chl in comparison with that of expensive and unavailable antibiotics such as Pol, Gen, Nor and Cip. Even Kan and $\mathrm{Nal}$ although shows some in vitro activities in this study, they are equally ineffective due to their phamacodynamic or pharmacokinetic characteristics [56]. However, the susceptibility patterns of $P$. aeruginosa vary geographically, and susceptibility tests should be done as an alternative means to select antimicrobial therapy [57]. According to this finding, Nor, Gen, Pol and Cip may be used as drug choice for empirical treatment. On the other hand, Amp, Tet, Sxt and Chl may not be used as the drugs of choice for the treatment of $P$. aeruginosa infection unless culture and sensitivity tests are done prior to treatment. The high prevalence of multidrug resistant indicates a serious need for broad-based, local antimicrobial resistance surveillance for continuous tracking of antibiotic resistance trends among all clinical relevant isolates and introduction of effective interventions to reduce multidrug resistance in such pathogens [58-60].

The occurrence of resistant strains in this study may be the spread use of these drugs. This may cause selective pressure of resistance problems on the enteric bacteria as a whole circulating in the community [61].

Culture and drug sensitivity results generally determine the choice of antibiotic for enteric bacterial infections. The choice of antimicrobial agents should be dictated by local resistance patterns and the patients' history antibiotic exposure [62,63]. Regardless of the choice of antibiotics, doses should be selected to maximize serum levels for enhanced activity. Combination therapy is also recommended to prevent the emergency of resistant strains. However, the effectiveness of combination therapy in preventing the emergency of antibiotic resistance in $P$. aeruginosa infections remains controversial. According to Carmeli et al. [64], combination therapy was not associated with a disease in the emergency of resistance. On the other hand, Jacobson et al. [65] found that combination therapy was associated with less frequent development of resistance than mono-therapy.

In this study, high prevalence of $P$. aeruginosa was observed in diarrheic patients with HIV infection suggesting that there is high human fecal contamination. This calls for efforts for strengthening control programs such as quality sanitation at community level to reduce risk factors of acquiring this diarrhoeagenic bacterium. In addition, routine examination of stool for $P$. aeruginosa with sensitivity test could significantly benefit the HIV infected and uninfected individuals in reducing morbidity and improving quality of life. This study was the first of its kind on the prevalence and antimicrobial responses of $P$. aeruginosa in HIV-1 positive and negative diarrhoea patients in Ethiopia. Therefore, the information obtained in this study is significant for empirical treatment of diarrheic patients' affected $P$. aeruginosa.

In this finding, Amp, Tet, Sxt and Chl may not be used for the treatment of $P$. aeruginosa infection, unless culture and sensitivity tests are done prior to treatment. In underdeveloped countries like Ethiopia, besides limiting therapeutic options and the high cost of alternative effective agents, resistant organisms may lead to longer hospitalization and an increased risk of death. The development of new antimicrobial agents may offer short-term solution to this problem but in the long run more effective measures such as health education and further research on the prevention of infections through quality sanitation, vaccination and immunization should be emphasized. Based on this study, I would recommend that public health measures should continue to emphasize the importance of environmental and personal hygiene.

\section{Acknowledgment}

The author would like to acknowledge the University of Gondar Presidents office and the research and Publication Office for their facilities and financial support to the experimental work. I am extremely grateful to Dr Mulugeta Aemero for his assistance in reviewing the manuscript.

\section{References}

1. UNAIDS/WHO (2007) AIDS epidemic update: Joint United Nations Programme on HIVIAIDS (UNAIDS) and World Health Organization (WHO).

2. Maureen Engelbrecht (2007) A survey on HIVIAIDS in Ethiopia. AIDS in Ethiopia 6th report, Ministry of Health. June, 2006.

3. UNAIDS (2005) 2005 report on the global HIVIAIDS epidemic: 5 th global.

4. Daniel F (2004) HIV associated opportunistic infections in Ethiopia. Faculty of Medicine, Addis Ababa University.

5. Kulkarni SV, Kairon R, Sane SS, Padmawar PS, Kale VA, et al. (2009) Opportunistic parasitic infections in HIV/AIDS patients presenting with diarrhoea by the level of immunesuppression. Indian J Med Res 130: 63-66.

6. Kosek M, Bern C, Guerrant RL (2003) The global burden of diarrhoeal disease as estimated from studies published between 1992 and 2000. Bull World Health Organ 81: 197-204.

7. UNAIDS (2008) Report on the global AIDS epidemic.

8. Thomas PD, Forbes A, Green J, Howdle P, Long R, et al. (2003) Guidelines for the investigation of chronic diarrhea, 2nd edition. Gut 52: V1-15.

9. May GR, Gill MJ, Church DL, Sutherland LR (1993) Gastrointestinal symptoms in ambulatory HIV-infected patients. Dig Dis Sci 38: 1388-1394.

10. Joint United Nations Program on HIVIAIDS/ World Health Organization (UNAIDS/WHO) (2005) AIDS epidemic update.

11. Semba RD, Caiaffa WT, Graham NM, Cohn S, Vlahov D (1995) Vitamin A deficiency and wasting as predictors of mortality in human immunodeficiency virus-infected injection drug users. J Infect Dis 171: 1196-1202.

12. Fichtenbaum CJ, Woeltje KF, Powderly WG (1994) Serious Pseudomonas aruginosa infections in patients infected with human immunodeficiency virus: a case control study. Clin Infect Dis 19: 417-422.

13. Todar K (2008) Online textbook of bacteriology.

14. Todar K (2004) Outline textbook of bacteriology. University of WisconsinMadison department of bacteriology.

15. Baron AD, Hollander $H$ (1993) Pseudomonas aruginosa bronchopulmonary infection in late human immunodeficiency virus disease. Am Rev Respire Dis 148: 992-996.

16. Dropulic LK, Leslie JM, Eldred LJ, Zenilman J, Sears CL (1995) Clinica 
Citation: Andualem B (2012) The Isolation Rate of Pseudomonas aeruginosa Opportunistic Pathogen and their Antimicrobial Responses in HIV-1 Positive and Negative Diarrhoea Patients at North-West Part of Ethiopia. J AIDS Clinic Res 3:148. doi:10.4172/2155-6113.1000148

Page 6 of 7

manifestations and risk factors of Pseudomonas aeruginosa infection in patients with AIDS. J Infect Dis 171: 930-937.

17. Kielhofner M, Atmar RL, Hamill RJ, Musher DM (1992) Life-threatening Pseudomonas aruginosa infections in patients with human immunodeficiency virus infection. Clin infect Dis 14: 403-411.

18. Blondel-Hill E, Hery DA, Speert DP (2007) Psedomonas. In Murray PR, Baron EJ, Jorgensen JH, Landry ML, Pfaller MA) Manual of clinical microbiology, 9th ed. American Society for microbiology, Washington, D. C.

19. Shepp DH, Tang IT, Ramundo MB, Kaplan MK (1994) Serious Pseudomonas aeruginosa infection in AIDS. J Acquir Immune Defic syndr 7: 823-831.

20. Scuster MG, Norris AH (1994) Community-acquired Pseudomonas aeruginosa pneumonia in patients with HIV infection. AIDS 8: 1437-1441.

21. Weinstein RA, Nathan C, Gruensfelder R, Kabins SA (1980) Endemic aminoglycoside resistance in gram-negative bacilli: epidemiology and mechanisms. J Infect Dis 141: 338-345.

22. Gales AC, Jones RN, Turnidge J, Rennie R, Ramphal R (2001) Characterization of Pseudomonas aeruginosa isolates: occurrence rates, antimicrobia susceptibility patterns, and molecular typing in the global SENTRY Antimicrobial surveillance programme, 1997-1999. Clin Infect Dis 32: S146-S155.

23. Fekete T, Tumash H, Woodwell J, Satishchandran V, Truant A, et al. (1996) Comparative susceptibility of Klebsiella species, Enterobacter species, and Pseudomonas aeruginosa to 11 antimicrobial agents in a tertiary-care university hospital. Am J Med 100: 20S-25S.

24. Hilf M, Yu VL, Sharp J, Zuravleff JJ, Korvick JA, et al. (1989) Antibiotic therapy for Pseudomonas aeruginosa bacteremia: Outcome correlations in a prospective study of 200 patients. Am J Med 87: 540-546.

25. Neuhauser MM, Weinstein RA, Rydman R, Danziger LH, Karam G, et al. (2003) Antibiotic resistance among gram-negative bacilli in US intensive care units: implications for fluoroquinolone use. JAMA 289: 885-888.

26. Itokazu GS, Quinn JP, Bell-Dixon C, Kahan FM, Weinstein RA (1996) Antimicrobial resistance rates among aerobic gram- negative bacilli recovered from patients in intensive care units: evaluation of a national postmarketing surveillance program. Clin Infect Dis 23: 779-784.

27. Sencer RC (1996) An 8 year Microbe Base survey of the epidemiology, frequency and antibiotic susceptibility of Pseudomonas aeruginosa hospital isolates in the United Kingdom. J Antimicrob Chemother 37: 295-301.

28. Crouch Brewer S, Wunderink RG, Jones CB, Leeper KV Jr (1996) Ventilatorassociated pneumonia due to Pseudomonas aeruginosa. Chest 109: 10191029.

29. Thomas PD, Forbes A, Green J, Howdle P, Lony R, et al. (2003) Guideline for the investigation of chronic diarrhoea, 2nd edition. Gut 5: v1-15.

30. Fisseha B, Petros B, Woldemichael T, Mohammed H (1999) DiarrhoeaAssociated parasitic infectious agents in AIDS patients within selected Addis Ababa Hospitals. Ethiop J Health Dev 13: 169-174.

31. Awole M, Gegre Selassie S, Kassa T, Kibtu G (2003) Prevalence of intestinal parasites in HIV-infected adult parasites in Southwestern Ethiopia. Ethiop J Health Dev 17: 71-78.

32. (1997) Joint United Nations Programme on HIVIAIDS (UNAIDS)-WHO. Revised recommendations for the selection and use of HIV antibody tests. Wkly Epidemiol Rec 72: 81-87.

33. WHO (1991) Programme for control of diarrhoea diseases. Eighth programme report 1990-1991. WHO/CDD/92/38. Geneva.

34. Power DA, McCuen PJ (1988) Manual of BBL products and Laboratory products: Becton Dickinson Microbiology systems. New York Elsevier 6: 336337.

35. Bergey's Manual (1984) Bergey's manual of systematic bacteriology.

36. Bauer AW, Kirby WM, Sherris JC, Turck M (1966) Antibiotic susceptibility testing by a standardized single disk method. Am J Clin Pathol 45: 493-496.

37. Avril A (1994) Identification system for enterobacteriaceae and pther Gramnegative tods (api 20E): 3rd ed. IMPRIME 'ENFRANC.

38. National committee for Clinical Laboratory Standards (2002) Performance Standards for antimicrobial susceptibility testing. 8th Informational Supplement.
M100 S12. National committee for Clinical Laboratory Standards, Villanova, $\mathrm{Pa}$.

39. (1992) 1993 revised classification system for HIV infections and expanded surveillance case definition for AIDS among adolescents and adults. MMWR Recomm Rep 41: 1-19

40. Barrio J, Lecona M, Cosin J, Olalquiaga FJ, Hernanz JM, et al. (1996) Leishmania infection occurring in herpes zoster lesions in an HIV-positive patient. Br J Dermatol 134: 164-166.

41. Del Giudice P (1996) Leishmania infection occurring in herpes zoster lesions in an HIV positive patient. Br J Dermatol 135: 1005-1006.

42. Sommer A, Davidson FR, Annecy Accords (2002) Assessment and control of vitamin A deficiency: the Annecy Accords. J Nutr 132: 2845S-2850S

43. Colebunders RL, Latif AS (1991) Natural history and clinical presentation of HIV-1 infection in adults. AIDS 5: S103-112.

44. Mitra AK, Alvarez JO, Wahed MA, Fuchs GJ, Stephensen CB (1998) Predictors of serum retinol in children with shigellosis. Am J Clin Nutr 68: 1088-1094.

45. Andualem B, Kassu A, Moges F, Gedefaw M, Diro E, et al. (2007) Diarrhoeaassociated parasites in HIV-1 seropositive and sero-negative patients in a teaching hospital, Northwest Ethiopia. Ethiop Med J 45: 165-170.

46. Kloos H, Tesfayohaness TM (1993) Intestinal parasites in Ethiopia: The ecology of health and disease in Ethiopia. Oxford: West view Press.

47. WHO (1984) Manual for the disease control programs: Control of diarrhoea disease. WHO/CDD/SER/81.5 Rev 1: 3-5.

48. Fisseha B, Petros B, Woldemichael T, Mohammed H (1999) Diarrhoeaassociated parasitic infectious agents in AIDS patients within Addis Ababa Hospitals. Ethiop J Health Dev 13: 169-174.

49. Witt DJ, Craven DE, McCabe WR (1987) Bacteria infections in adult patients with the acquired immune deficiency syndromes (AIDS) and AIDS-related complex. Am J Med 82: 900-906.

50. Osazuwa F, Osazuwa EO, Imade PE, Dirisu JO, Omoregie R, et al. (2011) Occurrence of extended spectrum beta-lactamase producing gram negative bacteria in HIV AIDS infected patients with urinary and gastrointestinal tract infections in Benin metropolis. Research Journal of Pharmaceutical, Biological and Chemical Sciences 2: 230-234.

51. Olayink BO, Oloitola OS, Olayinka AT, Agada EA (2004) Antibiotic susceptibility pattern and multiple antibiotic resistance index of Pseudomonas aeruginosa urine isolates from a university teaching hospital. Afr J Clin Exper Microbiol 5 198-202.

52. Hernandez K, Seas C, Bazan E, Zegarra R, Tapia E, et al. (2004) Staphylococcus aureus, Pseudomonas aeruginosa and Acinetobacter baumannii, resistan patterns in intensive care units in a Peruvian hospital. International congress on Infectious diseases 11th, March 4-7, Cancun: Mexico.

53. Meynard JL, Bubut F, Guiguet M, Batisse D, Lalande V, et al. (1999) Pseudomonas aeruginosa infection in human immunodeficiency virus infected patients. J Infect 38: 176-181

54. Fichtenbaum CJ, Woeltje KF, Powderly WG (1994) Serious Pseudomonas aeruginosa infections in patients infected with human immunodeficiency virus: A case-control study. Clin Infect Dis 19: 417-422.

55. Asamole-Osuocha CC (2006) A study on bacterial agents associated with diarrhoea cases in the federal capital territory, Abuja. Dissertation. Faculty of Medical Sciences, University of Jos.

56. Ball P (2000) Quinolone generations: natural history or natural selection? J Antimicrob Chemother 46: 17-24.

57. Jawetz, Melnick, Adelberg's (2010) Medical microbiology. Twenty-fifth edition Me Graw Hill. Pp 229.

58. Aseffa A, Gedlu E, Asmelash T (1997) Antimicrobial resistance of prevalent Salmonella and Shigella strains in northwest Ethiopia. East Afr Med J 74: 708 713.

59. Moges AF, Genetu A, Mengistu G (2002) Antibiotic sensitivities of common bacterial pathogens in urinary tract infections at Gondar Hospital, Ethiopia. East Afr Med J 79: 140-142.

60. Yismaw G, Negeri C, Kassu A (2008) A five year antimicrobial resistance pattern observed in Shigella species isolated from stool samples in Gonda 
Citation: Andualem B (2012) The Isolation Rate of Pseudomonas aeruginosa Opportunistic Pathogen and their Antimicrobial Responses in HIV-1 Positive and Negative Diarrhoea Patients at North-West Part of Ethiopia. J AIDS Clinic Res 3:148. doi:10.4172/2155-6113.1000148

University Hospital, northwest Ethiopia. Trop Doct 38: 43-45.

61. Meynarad JL, Barhut F, Guiguent M, Batisse D, Lalande V, et al. (1999) Pseudomonas aeruginosa infection in human immunodeficiency virus infected patients. J Infect 38: 176-181.

62. Bennett JV (1980) Antibiotic use in animals and human salmonellosis. J Infect Dis 142: 631-633.

63. El Amari EB, Chamot E, Auckenthaler R, Pechère JC, Van Delden C (2001) Influence of previous exposure to antibiotic therapy on the susceptibility pattern of Pseudomonas aeruginosa bacteremic isolates. Clin Infect Dis 33: 18591864.
64. Carmeli Y, Troillet N, Eliopoulos GM, Samore MH (1999) Emergence of antibiotic-resistant $P$ seudomonas aeruginosa: comparison of risks associated with different antipseudomonal agents. Antimicrob Agents chemother 43: 13791382.

65. Jacobson KI, Cohen SH, Inciardi JF, King JH, Lippert WE et al. (1995) The relationship between antecedent antibiotic use and resistance to extendedspectrum cephalosporins in group I beta-lactamase-producing organisms. Clin Infect Dis 21: 1107-1113. 